\title{
Improving Nutrition Utilization and Meat Quality of Broiler Chickens Through Solid-State Fermentation of Agricultural By-Products by Aureobasidium Pullulans
}

-Author(s)

\author{
Lee $\mathrm{MT}^{\mathrm{I}}$ \\ Lai LP' \\ Lin WC' \\ Ciou JY" \\ Chang SCIII \\ Yu B' \\ Lee TT'
}

Department of Animal Science, National Chung Hsing University, Taichung, Taiwan

" Department of Food Science, Tung Hai University, Taichung, Taiwan

III Kaohsiung Animal Propagation Station, Livestock Research Institute, Council of Agriculture, Taiwan

\section{Mail Address}

Corresponding author e-mail address Tzu-Tai Lee

Department of Animal Science, National Chung Hsing University, 250 KuoKuang Road, Taichung 402, Taiwan.

Tel: $\quad$ +886422870613

Email: ttlee@dragon.nchu.edu.tw

\section{nKeywords}

Mushroom stalk residue, soybean hull, Aureobasidium pullulans, digestibility, meat water holding capacity.

\section{ABSTRACT}

A 35 d trial was conducted to evaluate the effects of dietary supplementation of co-fermented agricultural by-products, soybean hulls and Pleurotus eryngii stalk residue (PESR), with Aureobasidium pullulans on nutrients digestibility and meat quality in broilers fed on conventional corn-soybean meal basal diet. A total of 4001 -d-old Ross broilers were allotted to 4 dietary treatments with 4 replicate pens (25 birds per pen). Birds were fed the corn-soybean meal diets supplemented with $0 \%$ (CON), $0.5 \%$ fermented soybean hulls $(0.5 \%$ $\mathrm{FSBH}), 0.5 \%$ fermented soybean hulls partially replaced with PESR $(0.5 \%$ FSHP) and $1.0 \%$ FSHP. The broilers fed on the diet that contained fermented products had higher total tract apparent digestibility for hemicellulose than those on CON $(p<0.05)$. Meanwhile, the birds fed on $0.5 \%$ FSHP also showed the lightest duodenum and jejunum weight among all groups. Compared with the CON, the inclusion of $1.0 \%$ FSHP in the diet significantly decreased ammonia $\mathrm{N}$ concentration in cecum followed by $0.5 \%$ FSHP and subsequent $0.5 \%$ FSBH group. Dietary supplementation of fermented products significantly improved WHC and increased protein content in meat as compared with the CON. Moreover, the fat content in meat decreased in the broilers that received $0.5 \% \mathrm{FSBH}$ and $1.0 \% \mathrm{FSHP}$. In conclusion, dietary supplementation of co-fermented agricultural by-products, PESR and soybean meal, could improve the digestibility of hemicellulose and decrease the cecal ammonia N concentration; moreover, the increased WHC and protein level as well as decreased fat content in meat suggested the promising utilization of these low-cost materials as broiler feed additives.

\section{INTRODUCTION}

The advantageous nutrient characteristics of soybean meal makes it an ideal ingredient in poultry feed. These include its high crude protein and energy content; due to the fat and low fiber content, as well as the high digestibility of well-balanced amino acid profile provides (Nahashon \& Kilonzo-Nthenge, 2013). However, the increasingly high cost of such conventional feedstuff urges the need for more economic and even locally available alternatives in the development and expansion of poultry enterprises. With alternative diets, poultry productivity is often poor due to nutrient deficiencies, accompanied by the presence of anti-nutritive factors like non-starch polysaccharides (NSPs), which monogastric animals have difficulty digesting (Barros et al., 2015). Soybean hulls, another processing by-product that represents about $8-10 \%$ of its whole composition, are a common replacement for ruminant forage in view of their high fiber concentration. Soybean hulls are made up of $60.3 \%$ of neutral detergent fiber (NDF), $44.6 \%$ of acid detergent fiber (ADF) and 2.5\% lignin (NRC, 2001). The prevalent NSPs located in the hulls are galactomannan, cellulose and xylan (Knudsen, 
2014). Negative effects of those NSPs on the poultry industry have been demonstrated, including retarded growth performance and a resulting poor meat quality (Zhang et al., 2014). These may be attributed to the physical barrier NSPs provide, increasing gut viscosity and compromising nutrient digestion and absorption (Barros et al., 2015; Zang et al., 2014).

Exogenous enzymes have been researched and applied extensively to eliminate these adverse effects in poultry by reducing gut viscosity, subsequently increasing nutrient digestibility and improving endogenous enzyme activity (Zhang et al., 2014). However, since the exact effect of the enzyme interaction remain obscure and it is difficult to determine the amount of NSPs present in food, the results may hence be contentious (Albino et al., 2006). Additionally, supplementation with such enzymes may substantially increase the cost of feed (Liu et al., 2007). A number of agro-industrial residues have been considered as possible substrates for use in the cultivation of microorganisms that produce enzymes during solid-state fermentation (Lai et al., 2015). The yeast-like fungus Aureabasidium pullulans was shown to have considerable potential for producing a variety of hydrolytic enzymes, such as xylanase and mannanase (Zalar et al., 2008), both of which enhance the acceptability of NSP-containing materials and their nutritional value in poultry feed.

Currently, consumers are paying greater attention to some properties of food they consume, such as safety, health benefits and nutritional properties. As a result, low fat, high protein levels and greater freshness of broiler chickens are popular demands in current international markets (Lee et al., 2012). Edible mushroom have exploited for centuries to maintain health, increase longevity and for lots of medical virtue attributed to their biologically active compounds (Valverde et al., 2015). Pleurotus eryngii (P. eryngii) have rapidly become a highly valued source of dietary fiber and other nutrients in Europe, Asia and North America (Lee et al., 2015). On top of that, P. eryngii has also been identified as a health food since its low in lipid/ fat and calories (Lee et al., 2015). In Taiwan, where it is commercially available, P. eryngii cultivation produces approximately 30 million packs annually (Wang, 2009). While the fruiting bodies of mushrooms mature, the stalks would be removed, thereby contributing to bulk of residual by-product. Previous reports showed that dried $P$. eryngii stalk residue (PESR) possessed active compounds that could potentially improve the meat quality of broiler chickens (Lee et al., 2012). Moreover, our previous study showed that the bioactive metabolite properties of PESR and soybean hulls co-fermented with Aureobasidium pullulans could improve body weight gain and promote optimal intestinal morphology in broiler chickens (Lai et al., 2015). However, the effects of the fermented materials on nutrient digestibility, ammonia nitrogen concentration and meat quality in chickens were not evaluated. That said, promising results may pave the way for this valuable, yet low cost material to become a sustainable feed additive.

The objective of this study, therefore, was to determine whether solid-state fermentation (SSF) of soybean hulls and PESR with $A$. pullulans could alleviate the negative effect of NSPs on nutrient digestibility, thereby improving the meat quality of broiler chickens.

\section{MATERIALS AND METHODS}

\section{Experimental birds and housing}

A total of four hundred 1-d-old broiler chickens (Ross 308) were randomly assigned to 4 pens each containing 25 chicks. The experiment was also randomized to four dietary treatments. During the experimental period, the chicks were firstly raised at $34 \pm 1^{\circ} \mathrm{C}$ until the birds reached $7 \mathrm{~d}$ of age, and it was gradually decreased to $26 \pm 1^{\circ} \mathrm{C}$ until the birds reached $21 \mathrm{~d}$ of age; subsequently, the birds were maintained under natural conditions with an average temperature of $26.5^{\circ} \mathrm{C}$

\section{Feeding schedule and dietary composition}

The 35-d trial consisted of two phases, starter (1 to $21 \mathrm{~d}$ ) and finisher (22 to $35 \mathrm{~d}$ ) shown in Table 1. Chickens had free access to the diets (in the mash form) in the feeder, and water in the drinker was provided ad libitum as well. The experimental diets containing four different treatments were: un-supplemented control diet based on corn-soybean; and the other three were provided experimental diets based on the basal diet but containing an additional 0.5\% FSBH (500 units Mannanase/kg diets), 0.5\% FSHP (500 units Mannanase/kg diets) and 1.0\% FSHP (1000 units Mannanase/kg diets). The proximate composition was analyzed according to the AOAC (2000) and showed no major deviations from the calculated values. All the diets were formulated to meet or exceed the requirements suggested by the NRC (1994).

\section{Digestibility determination}

The birds underwent 3 days acclimatization period to the cages, during which time they were fed on a basal diet. The birds were 35-d-old at the commencement of the experiment for digestibility. After the acclimatization 
Table 1 - Ingredients and chemical composition of the experimental diets of broilers

\begin{tabular}{|c|c|c|}
\hline Ingredient & Starter diet & Finisher diet \\
\hline & \multicolumn{2}{|c|}{ - } \\
\hline Yellow corn & 45.48 & 44.32 \\
\hline Soybean meal (CP 44.0\%) & 42.87 & 3.7 \\
\hline SBH & 1 & 1 \\
\hline FSBH & 0 & 0 \\
\hline FSHP & 0 & 0 \\
\hline Wheat bran & 0 & 5 \\
\hline Soybean oil & 5.86 & 8.54 \\
\hline Calcium carbonate & 1.6 & 1.37 \\
\hline Monocalcium phosphate & 1.9 & 1.6 \\
\hline $\mathrm{DL}^{- \text {Methionine }}$ & 0.39 & 0.33 \\
\hline$L^{-L y s i n e-H C l}$ & 0.22 & 0.16 \\
\hline $\mathrm{NaCl}$ & 0.4 & 0.4 \\
\hline Choline-Cl & 0.08 & 0.08 \\
\hline Vitamin premix $^{1}$ & 0.1 & 0.1 \\
\hline Mineral premix ${ }^{2}$ & 0.1 & 0.1 \\
\hline Total & 100 & 100 \\
\hline \multicolumn{3}{|l|}{ Calculated nutrient value } \\
\hline $\mathrm{ME}, \mathrm{kcal} / \mathrm{kg}$ & 3050 & 3175 \\
\hline Crude protein, \% & 23 & 21 \\
\hline Calcium, \% & 1.05 & 0.9 \\
\hline Total Phosphorus, \% & 0.75 & 0.7 \\
\hline Available Phosphorus, \% & 0.5 & 0.45 \\
\hline Lysine, \% & 1.43 & 1.25 \\
\hline Methionine+Cystein, \% & 1.07 & 0.96 \\
\hline \multicolumn{3}{|l|}{ Analyzed nutrition value } \\
\hline Crude protein, \% & 23.3 & 21.1 \\
\hline Crude fat, \% & 7.83 & 8.48 \\
\hline Ash, \% & 31.2 & 31.7 \\
\hline Acid detergent fiber, \% & 5.5 & 5.9 \\
\hline
\end{tabular}

SBH: Soybean hulls; FSBH: Fermented soybean hulls; FSHP: Fermented soybean hulls/ Pleurotus eryngii stalk residue $(75: 25)$

' Supplied per kg of diet: Vit A 15000 IU; Vit. D3 3000 IU; Vit. E 30 mg; Vit. K3 4 mg; Riboflavin 8 mg; Pyridoxine 5 mg; Vit. B12 $25 \mu$; Ca-pantothenate 19 mg; Niacin 50 $\mathrm{mg}$; Folic acid $1.5 \mathrm{mg}$; Biotin $60 \mu \mathrm{g}$.

2 Supplied per kg of diet: $\mathrm{Co}\left(\mathrm{CoCO}_{3}\right) 0.255 \mathrm{mg}$; Cu (CuSO4.5H 0$) 10.8 \mathrm{mg}$; Fe (FeSO4. $\left.\mathrm{H}_{2} \mathrm{O}\right) 90$ mg; Zn (ZnO) 68.4 mg; $\mathrm{Mn}\left(\mathrm{MnSO} 4 \cdot \mathrm{H}_{2} \mathrm{O}\right) 90 \mathrm{mg} ; \mathrm{Se}\left(\mathrm{Na}_{2} \mathrm{SeO}_{3}\right) 0.18 \mathrm{mg}$

period, the birds were given their respective diets ad libitum for $3 \mathrm{~d}$. Birds were fasted $24 \mathrm{~h}$ prior to the exam. Chromic oxide $(0.2 \%)$ was added to all diets as a digestibility marker. Daily feed intake was recorded throughout the examination period. Whole excreta samples were collected, weighed and dried at $50^{\circ} \mathrm{C}$ for $48 \mathrm{~h}$. The feed and dried excreta samples were ground to pass through a 40 mesh screen and mixed thoroughly before analysis. Digestibility coefficients for dry matter and crude protein were determined as above description, and then for the hemicellulose digestibility was calculated by NDF subtract ADF.

\section{Blood characteristics}

At the end of the experiment, four broilers were randomly selected from each treatment (one birds per pen) for sampling. The blood samples were collected by jugular vein puncture from each bird, and then stored at $-20^{\circ} \mathrm{C}$ until analysis. Samples for serum analysis were centrifuged at $3000 \times \mathrm{g}$ for 15 min to separate the serum. The concentration of total cholesterol, triglyceride, and low-density lipoprotein (LDL) cholesterol in the serum samples were analyzed with an automatic biochemical analyzer (Hitochi, 7150 auto-analyzer, Hitachi, Tokyo, Japan).

\section{Relative organs weight}

Subsequently, the same birds were weighed individually and bled via the brachial vein. The duodenum, jejunum, ileum, cecum, liver, spleen and bursa were removed and weighed. The relative organ weight was expressed as a percentage of body weight. Meanwhile, muscles from the breast and thigh fillets were packed in sealable plastic bags individually and stored at $4^{\circ} \mathrm{C}$ for meat quality analysis.

\section{Ammonia concentration in excreta and cecum}

The ammonia concentrations of the cecal digesta and excreta were assayed using the phenolhypochlorite-nitroprusside method. Briefly, cecal digesta or excreta $(1 \mathrm{~g}$ ) were mixed with $4 \mathrm{ml} 25 \%$ meta-phosphoric acid and then centrifuged at 3000 $\times \mathrm{g}$ for $10 \mathrm{~min}$. The $25 \mu \mathrm{L}$ supernatant was mixed with $50 \mathrm{ml}$ phenol-nitroprusside reagent (containing $5 \mathrm{~g} / \mathrm{L}$ phenol and $0.25 \mathrm{~g} / \mathrm{L}$ sodium nitroprusside) and $5 \mathrm{ml}$ alkaline hypochlorite solution (containing $25 \mathrm{~g}$ of $\mathrm{NaOH}$ and $16.8 \mathrm{~mL}$ of sodium hypochlorite solution) at $37^{\circ} \mathrm{C}$ for $15 \mathrm{~min}$, and then the absorbance of the resulting solution was measured at $630 \mathrm{~nm}$ for determining the ammonia concentration.

\section{Measurements of meat quality}

Meanwhile, the breast and leg were excised and placed in plastic bags; then freely suspended using a steel wire hook and stored at $4^{\circ} \mathrm{C}$. Care was taken to minimize the contact between the muscle and the inside surface of the bag. Twenty-four $h$ later, the water holding capacity (WHC) of samples (breast and thigh) were estimated by determining the amount of expressible juice using a modified filter paper press method. A raw meat sample of breast and thigh weighing approximately $1.0 \mathrm{~g}$ was placed between 18 pieces of 11-cm-diameter filter paper, which was then pressed at $35 \mathrm{~kg}$ for $6 \mathrm{~min}$. The amount of expressed 
juice was defined as the weight loss after pressing and presented as a percentage of the initial sample weight.

\section{Statistical analysis}

The data was analyzed by performing ANOVAs for completely randomized designs using the GLM procedure. Duncan's multiple range test using the Statistical Analysis System software package (SAS, 2004). The differences were considered to be significant at $p<0.05$.

\section{RESULTS}

\section{Total tract apparent digestibility}

Table 2 represents the effects of supplementation of FSBH and FSHP in broiler diet on total tract apparent digestibility after $35 \mathrm{~d}$. There were no significant differences in total digestibility for dry matter and protein between fermented products supplementation and control group. The birds that received 1.0\% FSHP had the lowest digestibility of NDF than others, and the ADF digestibility in broilers fed on fermented products were all lower than the corresponding control group. However, it is noteworthy that digestibility of hemicellulose increased with inclusion of fermented products into broiler diet compared with control $(p<0.05)$.

\section{Relative weight of small intestine, ceca and immune organs}

Table 3 presents the effects of supplementation of FSBH and FSHP in diet on relative weight of small intestine and ceca after $35 \mathrm{~d}$. The addition of $0.5 \%$ FSHP into the diets significantly reduced $(p<0.05)$ the relative weight of duodenum, jejunum and ileum by day 35 as compared to other treatments; lower cecal weight was observed in both $0.5 \% \mathrm{FSBH}$ and $0.5 \%$ FSHP addition $(p<0.05)$. Additionally, no effects were detected on immune organs such as liver, spleen and bursa due to FSBH and FSHP supplementation ( $p>0.05$ ).

Table 2 - Effect of fermented soybean hull (FSBH) and soybean hulls/Pleurotus eryngii (75:25, FSHP) supplemented in diet on the nutrient digestibility (\%) of $35 \mathrm{~d}$-old broilers

\begin{tabular}{|c|c|c|c|c|c|}
\hline \multirow{2}{*}{ Item ${ }^{1}$} & \multicolumn{4}{|c|}{ Experimental diets } & \multirow{2}{*}{$\mathrm{SEM}^{2}$} \\
\hline & Control & $\mathrm{FSBH}, 0.5 \%$ & FSHP, $0.5 \%$ & FSHP, $1.0 \%$ & \\
\hline Dry matter & $76.4 \pm 1.91$ & $76.2 \pm 1.40$ & $76.9 \pm 1.20$ & $76.9 \pm 1.01$ & 0.41 \\
\hline Protein & $63.7 \pm 7.87$ & $64.1 \pm 2.96$ & $62.8 \pm 4.11$ & $62.1 \pm 3.80$ & 1.39 \\
\hline NDF & $86.1 \pm 0.84^{a}$ & $86.3 \pm 0.65^{a}$ & $86.7 \pm 1.17^{a}$ & $82.9 \pm 0.91^{b}$ & 0.27 \\
\hline ADF & $30.1 \pm 2.92^{\mathrm{a}}$ & $22.2 \pm 3.10^{b}$ & $23.3 \pm 6.43^{b}$ & $18.7 \pm 3.78^{b}$ & 1.67 \\
\hline Hemicellulose & $58.9 \pm 5.21^{b}$ & $76.1 \pm 9.63^{a}$ & $75.9 \pm 7.98^{a}$ & $67.8 \pm 4.31^{a}$ & 2.79 \\
\hline
\end{tabular}

'Results are given as the means of 4 pens for 4 birds each pen. Control: corn-soybean meal; FSBH: fermented 100\% Soybean hulls; FSHP: fermented 75\% Soybean hulls in combination with $25 \%$ Pleurotus eryngii stalk residue.

2SEM = standard error of the mean.

$\mathrm{a}, \mathrm{b}$ Means within the same rows without the same superscript letter are significantly different $(p<0.05)$.

Table 3 - Effect of fermented soybean hull (FSBH) and soybean hulls/Pleurotus eryngii (75:25, FSHP) supplemented in diet on the relative organs weight (\%) of $35 \mathrm{~d}$-old broilers

\begin{tabular}{|c|c|c|c|c|c|}
\hline \multirow{2}{*}{ Item ${ }^{1}$} & \multicolumn{4}{|c|}{ Experimental diets } & \multirow{2}{*}{$\mathrm{SEM}^{2}$} \\
\hline & Control & $\mathrm{FSBH}, 0.5 \%$ & FSHP, $0.5 \%$ & FSHP, $1.0 \%$ & \\
\hline Duodenum & $0.61 \pm 0.06^{a}$ & $0.60 \pm 0.07^{a}$ & $0.53 \pm 0.06^{b}$ & $0.59 \pm 0.07^{a}$ & 0.02 \\
\hline Jejunum & $1.10 \pm 0.08^{\mathrm{a}}$ & $0.99 \pm 0.16^{\mathrm{ab}}$ & $0.89 \pm 0.10^{b}$ & $1.02 \pm 0.13^{\mathrm{a}}$ & 0.03 \\
\hline Ileum & $0.70 \pm 0.10$ & $0.67 \pm 0.11$ & $0.57 \pm 0.04$ & $0.67 \pm 0.05$ & 0.04 \\
\hline Cecum & $0.29 \pm 0.01^{\mathrm{a}}$ & $0.26 \pm 0.01^{\mathrm{ab}}$ & $0.24 \pm 0.04^{b}$ & $0.27 \pm 0.02^{\mathrm{ab}}$ & 0.01 \\
\hline Liver & $2.89 \pm 0.19$ & $2.87 \pm 0.53$ & $2.90 \pm 0.40$ & $2.75 \pm 0.30$ & 0.10 \\
\hline Spleen & $0.12 \pm 0.01$ & $0.13 \pm 0.04$ & $0.14 \pm 0.04$ & $0.14 \pm 0.04$ & 0.01 \\
\hline Bursal & $0.16 \pm 0.03$ & $0.18 \pm 0.04$ & $0.15 \pm 0.02$ & $0.16 \pm 0.02$ & 0.01 \\
\hline
\end{tabular}

'Results are given as the means of 4 pens for 4 birds each pen. Control: corn-soybean meal; FSBH: fermented 100\% Soybean hulls; FSHP: fermented 75\% Soybean hulls in combination with $25 \%$ Pleurotus eryngii stalk residue.

${ }^{2} \mathrm{SEM}=$ standard error of the mean.

${ }^{a, b}$ Means within the same rows without the same superscript letter are significantly different $(p<0.05)$. 


\section{Ammonia concentration in excreta and cecum}

Table 4 shows the effects of supplementation of FSBH and FSHP in the diet on the ammonia $N$ concentration of excreta and cecum after $35 \mathrm{~d}$. In comparison with the birds fed on the conventional corn-soybean meal diet, no significant differences were demonstrated in the excreta ammonia concentrations in either fermented products-treated groups. Nevertheless, dietary supplementation of $1.0 \%$ FSHP significantly decreased ammonia concentration in the cecum as compared with the corresponding control group, followed by $0.5 \%$ FSHP and the subsequent $0.5 \% \mathrm{FSBH}$.

Table 4 - Effect of fermented soybean hull (FSBH) and soybean hulls/Pleurotus eryngii (75:25, FSHP) supplemented in diet on the ammonia $\mathrm{N}$ concentration (mmole/g) of excreta and cecum in $35 \mathrm{~d}$-old broilers

\begin{tabular}{lccccc}
\hline \multirow{2}{*}{ Item $^{1}$} & \multicolumn{4}{c}{ Experimental diets } & \multicolumn{2}{c}{ SEM ${ }^{2}$} \\
\cline { 2 - 5 } & Control & FSBH, 0.5\% & FSHP, 0.5\% & FSHP, $1 \%$ & $45.0 \pm 6.03^{\mathrm{a}}$ \\
Excreta & $40.3 \pm 5.56^{\mathrm{ab}}$ & $45.7 \pm 5.02^{\mathrm{a}}$ & $38.0 \pm 7.07^{\mathrm{b}}$ & 2.01 \\
Cecum & $104.2 \pm 10.23^{\mathrm{a}}$ & $83.3 \pm 3.58^{\mathrm{b}}$ & $73.5 \pm 7.51^{\mathrm{c}}$ & $40.8 \pm 5.32^{\mathrm{d}}$ & 3.72 \\
\hline
\end{tabular}

'Results are given as the means of 4 pens for 4 birds each pen. Control: corn-soybean meal; FSBH: fermented 100\% Soybean hulls; FSHP: fermented $75 \%$ Soybean hulls in combination with $25 \%$ Pleurotus eryngii stalk residue.

${ }^{2} \mathrm{SEM}=$ standard error of the mean

$a, b, c$ Means within the same rows without the same superscript letter are significantly different $(p<0.05)$.

\section{Blood characteristics}

Table 5 shows the effects of supplementation of $\mathrm{FSBH}$ and FSHP in the diet on the blood characteristics after $35 \mathrm{~d}$. There were no significant differences in total cholesterol, triglyceride or LDL cholesterol concentrations among all experimental groups.

\section{Water holding capacity (WHC), and protein and fat content in meat}

Table 6 shows the effects of supplementation of FSBH and FSHP in the diet on the WHC and protein and fat content in breast and thigh muscles after 35 d. The insignificant result was only observed in the

Table 5 - Effect of fermented soybean hull (FSBH) and soybean hulls/Pleurotus eryngii (75:25, FSHP) supplemented in diet on the on the blood characteristics $(\mathrm{mg} / \mathrm{dL})$ of $35 \mathrm{~d}$-old broilers

\begin{tabular}{lccccc}
\hline \multirow{2}{*}{ Item ${ }^{1}$} & \multicolumn{2}{c}{ Experimental diets } & \multicolumn{1}{c}{ SEM ${ }^{2}$} \\
\cline { 2 - 5 } & Control & FSH, 0.5\% & FSHP, 0.5\% & FSHP, 1.0\% & 4.59 \\
\hline T-CHO & $101.7 \pm 3.79$ & $93.3 \pm 17.39$ & $95.7 \pm 2.08$ & $99.0 \pm 3.61$ & 4.90 \\
TG & $62.0 \pm 2.83$ & $60.0 \pm 12.73$ & $56.7 \pm 4.04$ & $43.3 \pm 13.65$ & $16.3 \pm .51$ \\
LDL & $16.7 \pm 6.51$ & $11.3 \pm 2.08$ & $12.0 \pm 2.65$ & 2.03 \\
\hline
\end{tabular}

'Results are given as the means of 4 pens for 1 birds each pen. Control: corn-soybean meal; FSBH: fermented 100\% Soybean hulls; FSHP: fermented 75\% Soybean hulls in combination with 25\% Pleurotus eryngii stalk residue.

${ }^{2} \mathrm{SEM}=$ standard error of the mean.

T-CHO: total cholesterol, TG: Triglycerides; LDL: low density lipoprotein.

crude fat of the thigh muscles among the treatments. In comparison with birds fed on the control diet, the protein content of breast was significantly increased $(p<0.05)$ in $0.5 \%$ FSHP followed by $0.5 \%$ FSBH group. Moreover, all of the dietary fermented productssupplemented groups had the highest content of protein in thigh muscle as compared with the control group. The results also suggested that broiler administration of $0.5 \%$ FSHP could slightly reduce crude fat in breast; whilst obtained the lowest level in the birds that received $0.5 \% \mathrm{FSBH}$ or $1.0 \% \mathrm{FSHP}$ $(p<0.05)$.

\section{DISCUSSION}

The effects on enzyme secretion and nutrient digestibility when fibrous components are included in the poultry diet are up for debate (Mateos et al., 2012). Xylan and mannan are the main NSPs that increase gastrointestinal viscosity, resulting in a reduced diffusion rate of digestive enzymes and substrates. This prevents enzymatic interaction on the intestinal mucosa surface, thereby reducing digestion, absorption of nutrients and even broiler productivity (Liu et al. 2007; Lai et al. 2015). As a result, greater attention is paid 
Table 6 - Effect of fermented soybean hull (FSBH) and soybean hulls/Pleurotus eryngii (75:25, FSHP) supplemented in diet on proximate composition (\%) and water holding capacity (WHC, \%) of breast and leg meat of $35 \mathrm{~d}$-old broilers

\begin{tabular}{|c|c|c|c|c|c|c|}
\hline \multirow{2}{*}{ Item ${ }^{1}$} & & \multicolumn{5}{|c|}{ Treatment } \\
\hline & & Control & FSBH, $0.5 \%$ & FSHP, $0.5 \%$ & FSHP, $1.0 \%$ & $\mathrm{SEM}^{2}$ \\
\hline \multirow[t]{3}{*}{ Breast } & WHC & $63.26 \pm 1.43^{b}$ & $65.55 \pm 2.11^{a}$ & $66.06 \pm 1.27^{a}$ & $66.66 \pm 1.36^{a}$ & 1.99 \\
\hline & Protein & $21.94 \pm 0.60^{b}$ & $22.83 \pm 0.49^{a}$ & $22.34 \pm 0.65^{a b}$ & $22.15 \pm 0.51^{b}$ & 0.37 \\
\hline & Crude fat & $2.01 \pm 0.33^{a}$ & $1.43 \pm 0.35^{b}$ & $1.7 \pm 0.42^{\mathrm{ab}}$ & $1.45 \pm 0.32^{b}$ & 0.14 \\
\hline \multirow[t]{2}{*}{ Leg } & WHC & $59.22 \pm 1.81^{c}$ & $63.31 \pm 1.07^{b}$ & $65.32 \pm 1.50^{\mathrm{a}}$ & $63.21 \pm 1.09^{b}$ & 2.16 \\
\hline & Protein & $17.35 \pm 0.67^{b}$ & $18.46 \pm 0.55^{a}$ & $18.39 \pm 1.07^{a}$ & $18.18 \pm 0.56^{a}$ & 0.63 \\
\hline$\otimes$ & Crude fat & $5.2 \pm 1.03$ & $4.13 \pm 0.49$ & $4.99 \pm 1.23$ & $4.18 \pm 0.59$ & 1.09 \\
\hline
\end{tabular}

'Results are given as the means of 4 pens for 2 birds each pen. Control: corn-soybean meal; FSBH: fermented 100\% Soybean hulls; FSHP: fermented 75\% Soybean hulls in combination with $25 \%$ Pleurotus eryngii stalk residue.

2SEM = standard error of the mean.

$a, b, c$ Means within the same rows without the same superscript letter are significantly different $(p<0.05)$.

to enzyme use in livestock nutrition. In the current study, the dietary inclusion of fermented products significantly improved hemicellulose digestibility (Table 2 ), while a relatively lighter gut weight was observed in groups that received $0.5 \% \mathrm{FSBH}$ and $0.5 \%$ FSHP when compared to those fed only the basal diet (Table 3). Our findings suggest that exogenous hemicellulases produced by the SSF of soybean hull and PESR with $A$. pullulans partially eliminated the anti-nutritional factors present in substrates. This resulted in enhanced digestibility and diminished the deleterious effects on the gut, as well as enhancing the accessibility of nutrients by breaking down the cell wall (Beker et al., 2004; Chiang et al., 2003; Lee et al., 2015). Several studies have demonstrated the beneficial effects of xylanase and mannanase supplements on nutrient digestion in poultry. Esmaeilipour et al. (2012) demonstrated that xylanase supplementation in wheat-based diets of broiler chickens significantly improved the apparent total tract nutrient digestibility of dry matter and protein. Similarly, Azarfar (2013) reported that supplementation with $\beta$-mannanase improved illeal nutrient digestibility of crude protein in broilers fed a corn-soybean diet. In our study, the lack of significant differences in the protein and dry matter results between those birds that received SSF products and those in the control group suggests that SSF with $A$. pullulans may indeed subdue the potentially compromising effects that agricultural byproducts have on digestion. Hemicellulose digestion is enhanced, possibly due to the fact that the hydrolytic enzymes produced disrupt the integrity of endosperm cell wall, further breaking down the highly viscous NSP and thus releasing trapped nutrients (Chiang et al., 2005). The beneficial impact of co-fermented products on NSPs is evidenced by the improvements in body weight gain and ileum morphology in birds fed $0.5 \%$ FSHP compared to those in the control group (Lai et al., 2015).

High ammonia nitrogen concentration may negatively disturb the growth and differentiation of intestinal epithelial cells accompanied by compromised nutrition digestibility, further increasing the risk of diarrhea (Younes et al., 1996; Beker et al., 2004). Moreover, there are considerable experimental studies that suggest atmospheric $\mathrm{NH}_{3}$ would affect the performance and projected disease susceptibility of poultry (Beker et al., 2004). Nitrogen metabolism in the colon is modulated by the metabolic activity of resident microflora which may be affected by the availability of substrate, particularly dietary carbohydrates (Younes et al., 1996). Undigested carbohydrates in ceca, the principal fermentation chamber in poultry gut, would be transformed into various products, including ammonia (Guo et al., 2003). Dietary NSPs may cause small intestine fermentation to reach excessive levels that may be detrimental to nutrient digestion and absorption (Liu et al., 2007; Zhang et al., 2014). Guo et al. (2003) reported that significantly higher ammonia levels were found in those materials which had higher protein content yet less carbohydrate available for cecal fermentation. In the current study, there was no difference in the total tract digestibility of protein among all groups. Moreover, chickens fed $1 \%$ FSHP had the lowest cecal ammonia nitrogen levels, followed by the $0.5 \%$ FSHP and $0.5 \%$ FSBH groups. 
These results demonstrate that the NSPs in SBH and PESR were hydrolyzed by the solid state fermentation into carbohydrates suitable for fermentation, ultimately resulting in the net utilization of $\mathrm{NH}_{3}$ for bacterial growth (Guo etal., 2003; Lai etal., 2015). The abundant amount of crude polysaccharides in PESR may be one of the factors impacting the level of fermentable carbohydrates; this highlights PESR's potential as an additive to the broiler diet (Lee et al., 2012). It is conceivable that feeding excess fiber to poultry may increase fermentation in the ceca, leading to cecal hypertrophy and impacting production (Mateos et al., 2012). However, no differences in the relative cecal weight were found between birds that received $0.5 \%$ FSBH, 1\% FSHP and the control diet. In fact, birds fed $0.5 \%$ FSHP had the lowest cecal weight overall. The commensurate ammonia nitrogen concentration in the excreta from the experimental treatment groups could further support the above phenomenon. Unabsorbed protein from the small intestine, together with excess indigestible carbohydrates, may enhance fecal nitrogen excretion (Younes et al., 1996). Therefore, the increase in fibrolytic enzymes seen in the current study after SSF may decrease gut viscosity, resulting in a better utilization of nutrients and decreasing the amount of organic matter in the excreta.

The accumulation of excess abdominal fat in broiler chickens is one of the major issue in the modern poultry industry since it is not only regarded as dietary energy waste and a residue with low economic value, but it also reduces the carcass yield (Fouad et al., 2013). In the current study, the relative fat content of the breast meat was significantly reduced when the diet was supplemented with $0.5 \% \mathrm{FSBH}$ or $1 \%$ FSHP. The possible relation between serum lipid metabolites and mushrooms has been extensively studied. In rats, the addition of mushrooms to a high cholesterol diet affected serum triglyceride and cholesterol levels and effectively averted cholesterol accumulation in the liver (Fukushima et al., 2000). In a study using mannooligosaccharide obtained from yeast, this effect was attributed to the hypocholesterolaemic agent inhibiting the rate-limiting enzyme activity for cholesterol synthesis (Mohamed et al., 2014). Fouad et al. (2013) further evaluated the effects of dietary supplementation with L-arginine on lipid-related properties; their results suggested a potential influence on blood cholesterol, triglyceride concentration and abdominal fat on a molecular level. Accordingly, the slight decrease in total serum cholesterol and triglyceride concentration in birds that received either
FSBH or FSHP may hereby make those parameters indicators for the fat content in meat. Previous literature reported that liver is the most important organ for fatty acid synthesis in avian species. Since almost $85 \%$ of the fat accumulated by growing birds is produced in the liver, an increase in liver weight could be related to an increased fat content (Molette et al., 2012). In the present study, there was no difference in liver weight among all the groups, suggesting that the addition of fermented products would not cause such undesirable effects on the end meat product, while still maintaining normal immune and health levels.

In light of the need for high quality meat to fulfill demands of industry and consumers, targeted feeding strategies which support positive development in major meat quality traits are valued. The ability of fresh meat to retain moisture is one of the most important quality characteristics in raw products, both from the consumer and processor's point of view (Bowker \& Zhuang, 2013). Loss in water-holding capacity (WHC) may cause liquid outflow that introduces loss of soluble nutrients and flavor (Lee et al., 2012; Bowker \& Zhuang, 2013; Suo et al., 2015), but also causes unappealing moisture accumulation in packaging, a less tender cooked product as well as reduced functionality in the manufacturing of further processed poultry products (Bowker \& Zhuang, 2013). As our results show, the higher protein percentage in both the breast meat of chickens fed $0.5 \% \mathrm{FSBH}$ and the leg meat of all three treatment groups is accompanied by a higher WHC. Muscle proteins are capable of holding many water molecules on their surface, a relationship which has been presented in previous literature (Bowker \& Zhuang, 2013). The improvement in the WHC might be related to the protection against oxidation (Mazaheri et al., 2014). Shi et al. (2010) reported that the addition of xylo-oligosaccharides (XOS) decreased drip loss in the breast and thigh muscle of broilers. Similar results were also found in a study by Suo et al. (2015), who suggested that such improvement could be attributed to an increased antioxidant capacity induced by XOS. Lee et al. (2012) reported that the phenolic compounds in PESR exert potentially antioxidant properties that slow lipid peroxidation and improve meat quality in broilers. The improved hemicellulose digestibility from SSF with $A$. pullulans may produce some oligosaccharides. This, combined with the phenolic content of PESR, could provide antioxidants to combat lipid peroxidation. Similar effects were reported by Mazaheri et al. (2014), the use of mushroom waste (Agaricus bisporus) resulted in a significant increase in WHC. 


\section{CONCLUSION}

Solid state fermentation (SSF) of soybean hulls and PESR with $A$. pullulans effectively lowers their undesirable NSP content by increasing hemicellulose digestibility, allowing broilers on a supplemented diet to maintain a duodenal and jejunal weight comparable to the control group's un-supplemented corn-soybean meal diet. A decrease in the ammonia nitrogen concentration in the cecum confirms this improved nutrient utilization, attributed to an enzyme augmentation after SSF. Finally, the higher protein level and improved WHC in meat accompanied by a lower fat content suggests that supplementation with cofermented by-product materials may result in optimal results for both the consumer and the processor.

\section{ACKNOWLEDGEMENT}

The authors thank the Ministry of Science and Technology (MOST 106-2313-B-005-048) for financially supporting this study.

\section{REFERENCES}

Albino LFT, Feres FA, Dionizio MA, Rostagno HS, Junior JGV, Carvalho DCO, et al. Uso de prebióticos à base de mananoligossacarídeo em rações para frangos de corte. Revista Brasileira de Zootecnia 2006;35:742749.

AOAC. Official methods of analysis. $17^{\text {th }}$ ed. Washington: Association of Official Analytical Chemist; 2000.

Azarfar A. Effect of hemicell enzyme on the performance, growth parameter, some blood factors and ileal digestibility of broiler chickens fed corn/ soybean-based diets. Journal of Cell and Animal Biology 2013;7:85-91.

Barros VRSM, Lana GRQ, Lana SRV, Lana AMQ, Cunha FSA, Neto JVE. $\beta$-mannanase and mannan oligosaccharides in broiler chicken feed. Ciência Rural 2015;45:111-117.

Beker A, Vanhooser SL, Swartzlander JH, Teeter RG. Atmospheric ammonia concentrationeffects on broiler growthand performance. The Journal of Applied Poultry Research 2004;13:5-9.

Bowker BC, Zhuang $\mathrm{H}$. Relationship between muscle exudate protein composition and broiler breast meat quality. Poultry Science 2013;92:1385-1392.

Chiang CC, Yu B, Chiou PWS. Effects of xylanase supplementation to wheat-based diet onthe performance and nutrient availability of broiler chickens. Asian-Australasian Journal of Animal Sciences 2005;18:11411146 .

Esmaeilipour O, Moravej H, Shivazad M, Rezaian M, Aminzadeh S, Van Krimpen MM. Effects of diet acidification and xylanase supplementation on performance, nutrient digestibility, duodenal histology and gut microflora of broilers fed wheat based diet. British Poultry Science 2012;53:235-244.

Fouad AM, El-Senousey HK, Yang XJ, Yao JH. Dietary L-arginine supplementation reduces abdominal fat content by modulating lipid metabolism in broiler chickens. Animal 2013;7:1239-1245.
Fukushima M, Nakano Y, Morii Y, Ohashi T, FujiwaraY, Sonoyama K. Hepatic LDL receptor mRNA in rats is increased by dietary mushroom (Agraicus bisporous) fiber and sugar beet fiber. Journal of Nutrition 2000;130:2151-2156.

Guo FC, Williams BA, Kwakkel RP, Verstegen MWA. In vitro fermentation characteristics of two mushroom species, an herb, and their polysaccharide fractions, using chicken cecal contents as inoculum. Poultry Science 2003;82:1608-1615.

Gao F, JiangY,ZhouGH, Han ZK. The effects of xylanase supplementation on performance, characteristics of the gastrointestinal tract, blood parameters and gut microflora in broilers fed on wheat-based diets. Animal Feed Science and Technology 2008;142:173-184

Knudsen KEB. Fiber and nonstarch polysaccharide content and variation in common crops used in broiler diets. Poultry Science 2014;93:23802393.

Lai LP, Lee MT, Chen JS, Yu B, Lee TT. Effects of co-fermented Pleurotus eryngii stalk residues and soybean hulls by Aureobasidium pullulans on performance and intestinal morphology in broiler chickens. Poultry Science 2015;94:2959-2969.

Lee TT, Chou JY, Chiang CJ,Chao YP, Yu B. Effect of Pleurotus eryngii stalk residue on the oxidative status and meat quality of broiler chickens. Journal of Agricultural and Food Chemistry 2012;60:11157-11163.

Lee TT, Ciou JY, Chen CN, Yu B. The effect of Pleurotus eryngii stalk residue dietary supplementation on layer performance, egg traits and oxidative status. Annals of Animal Science 2015;15:447-461.

Liu JR, Lai SF, Yu B. Evaluation of an intestinal Lactobacillus reuteri strain expressing rumen fungal xylanase as a probiotic for broiler chickens fed on a wheat-based diet. British Poultry Science 2007;48:507-514.

Mazaheri A, Shams Shargh M ,Dastar B, Zerehdaran S. Effect of different levels of mushroom waste (Agaricus bisporus) with or without probiotic on growth performance, carcass characteristics, and breast meat quality in broiler chickens. Poultry Science Journal 2014;2:125-138.

Molette C, Theron L, Marty-Gasset N, Fernandez X, Remignon H. Current advances in proteomic analysis of (fatty) liver. Journal of Proteomics 2012;75:4290-4295.

Mohame DS, Elkady MF, Hassanin KMA, Hashem KS. The ameliorative effects of L-carnitine and synbiotics on induced hyperlipidemia and oxidative stress in broilers. International Journal of Advanced Research 2014;2:378-390.

Nahashon S N, Kilonzo-Nthenge AK. Soybean in monogastric nutrition modifications to add value and disease prevention properties, soybean - bio-active compounds. In: El-Shemy HA, editor. Soybean - bioactive compounds. Rijeka: InTech; 2013. Available from: http://www. intechopen.com/books/soybean-bio-active-compounds/soybeanin-monogastric-nutrition-modifications-to-add-value-and-diseaseprevention-properties.

NRC - National Research Council. Nutrient requirements of poultry. 7th ed. Washington: National Academy of Science Press; 2001.

SAS Institute. SAS/STAT guide for personal computers. Version 9.0.1. Cary 2004.

Shi N. Effects of bacillus licheniformins, xylooligosaccharides and lactic acid on intestinal villiand intestinal microflora in broilers [thesis]. Jiaozuo (CHN): Henan Polytechnic University; 2010.

Suo HQ, Lin LU, Xu GH, Lin X, Chen XG, Xia RR, et al. Effectiveness of dietary xylo-oligosaccharides for broilers fed a conventional cornsoybean meal diet. Journal of Integrative Agriculture 2015;14:20502057. 
Lee MT, Lai LP, Lin WC, Ciou JY, Chang SC, Yu B, Lee TT
Improving Nutrition Utilization and Meat Quality of Broiler Chickens Through Solid-State Fermentation of Agricultural By-Products by Aureobasidium Pullulans
Valverde ME, Hernández-Pérez T, Paredes-López O. Edible mushrooms: improving human health and promoting quality life. International Journal of Microbiology 2015;2015:1-14.

Wang BC. Edible and medical value of mushrooms and their development of diversity products. International Journal of Microbiology 2009;18:3440 .

Mateos GG, Jiménez-Moreno E, Serrano MP, Lázaro RP. Poultry response to high levels of dietaryfiber sources varying in physical and chemical characteristics. The Journal of Applied Poultry Research 2012;21:156174.

Younes H, Demigné C, Behr SR, Garleh KA, Rémésy C. A blend of dietary fibers increasesurea disposal in the large intestine andlowers urinary nitrogen excretion inrats fed a low protein diet. The Journal of Nutritional Biochemistry 1996;7:474-480.

Zalar P, Gostinčar C, Hoog GS, Uršič V, Sudhadham M, Gunde-Cimerman N. Redefinition of Aureobasidium pullulans and its varieties. Studies in Mycology 2008;61:1-38.

Zhang L, Xu J, Lei L, Jiang $Y$, Gao F, Zhou GH. Effects of xylanase supplementation on growth performance, nutrient digestibility and non-starch polysaccharide degradation in different sections of the gastrointestinal tract of broilers fed wheat-based diets. AsianAustralasian Journal of Animal Sciences 2014;27:855-861. 
